\title{
A year's memories: The calendar effect in autobiographical recall
}

\author{
MATTHEW A. KURBAT \\ University of Pennsylvania, Philadelphia, Pennsylvania \\ STEVEN K. SHEVELL \\ University of Chicago, Chicago, Illinois \\ and \\ LANCE J. RIPS \\ Northwestern University, Evanston, Illinois
}

\begin{abstract}
When asked to recall autobiographical events from the past year, students tend to recall more incidents from the beginning and the end of school terms than from other periods. We investigated this calendar effect in Experiment 1 by comparing free recall at schools with different academic calendars. The event distributions tracked the individual calendars, helping to eliminate the possibility that the calendar effect is due to seasonal, nonschool factors, such as holidays. In Experiments 2-4, we checked explanations based on the ideas that events at term boundaries are more important or distinctive than others, that events are incorrectly dated too near the boundaries, and that boundaries serve as implicit cues for recall. These experiments revealed no evidence that importance or errors in dating could explain the effect. Manipulating cues, however, did change the size of the effect, implicating retrieval from very long-term memory as the effect's source. We suggest that when people have to search episodic memory, they consider their own calendar rhythms (such as a student's academic schedule) and let the temporal structure of their personal context guide their search.
\end{abstract}

There are times during the year when a lot happens. Events seem to occur with much greater frequency than usual, and we are surprised at how many things we have managed to do. We gave a talk at a conference, moved to a new condo, finished the paper we were working on, gave a birthday party for Dorothy, graded the finals, and turned in the grades. At other times nothing much happens. It is hard to remember that we initiated or even participated in anything in these stretches, so that in retrospect our yearly activities seem to go in periods of dense and of sparse patches.

Part of this rhythm derives from the work schedules we live under. Many occupations, especially in traditional cultures, have cyclical periods of activities that depend on natural events such as growing seasons. In such cultures, these activity patterns may even furnish people's methods for determining when events take place (Evans-Pritchard, 1940; Leach, 1961; Malinowski, 1927). In our culture, too, activity cycles dominate many occupations, even though

NSF Grant SES-841 1976 supported the research that we report in this paper. We are very grateful to Richard Block, Norman Bradburn, Martin Conway, Dan Crane, Paul Estin, Christi Frum, Evan Heit, Julie Johnson, Darlene McCampbell, Nick Mancini, David Pillemer, Hope Rhinestine, John Robinson, Neal Roese, Jeff Schank, Mike Shum, Laura Taalman, and Charlotte Vaughan for their help with these studies. Correspondence should be addressed to L. J. Rips, Department of Psychology, Northwestern University, 2029 Sheridan Road, Evanston, IL 60208 (e-mail: rips@nwu.edu).

-Accepted by previous editor, Geoffrey R. Loftus they are not necessarily used in reckoning the time of events. In addition to seasonal cycles in agriculture, strong seasonal phases occur in tourism, athletics, construction, and probably many other industries. If we are students or teachers, or have children in school, then the school year imposes a succession of activities associated with terms and vacations.

The notion that more happens in some periods than in others, however, is probably not literally true. It is notoriously difficult to differentiate events, and controversies abound concerning how to count them (Davidson, 1969; Goldman, 1970). Is going on a date with a friend and going to a movie with the friend one event or two? Moreover, people's division of experience into separate events (and their later recall of these events) may depend on their goals and beliefs (Hanson \& Hirst, 1989; Newtson, 1973). But whatever the correct method of counting events, the total number of events that happen to us in December is not likely to be much different from the number in August. We participate in events continuously; there are no chinks between events in which "nothing happens." Even months that seem slack consist of astronomical numbers of personal occurrences, many of them of course exceedingly trivial: shifting positions, changing gaze, uttering speech sounds, not to mention mental events (deciding to have another sandwich) and events that we participate in but do not initiate (being glanced at).

It seems highly improbable that portions of the year differ in the actual number of events that occur in them. Nevertheless, there could well be differences in the number of 
recalled events from different parts of the year, and it is the source of these memory differences (if any) that we intend to investigate. As we will see momentarily, students' (free-recalled) memories of their activities during a year fluctuate in phase with the school terms.

\section{The Calendar Effect}

In independent studies, Pillemer, Rhinehart, and White (1986) and Robinson (1986) discovered that when students have to free recall incidents from the past year or two, recalled events appear to be more frequent near the beginning and the end of school terms than at other times of the year. We will refer to this pattern of recalled events as the calendar effect. For example, Pillemer et al. (1986, Experiment 2) asked a group of Wellesley students (sophomores, juniors, and seniors) to describe four memories from their freshman year and then to date these events as accurately as possible. When plotted against the months of the year, the frequency distribution of these events exhibits a distinct peak in September, the students' first month in college, and a dip in January, when most students are away from campus. Pillemer, Goldsmith, Panter, and White (1988) repeated the study with groups of alumnae who had graduated 2,12 , and 22 years earlier and found similar distributions for their memories of freshmen year.

In a similar experiment at the University of Louisville, Robinson (1986) cued students with the names of the months of the year and required them to summarize as many personal memories as possible that had occurred during these months. Similar trends appeared in a separate experiment in which students free-recalled " 20 life experiences from the past year or two" and then dated them. In both studies the number of recalled events tended to peak in the months just prior to the ends of the two semesters (i.e., May and December) and in the month prior to the beginning of the first semester (August).

A comparison of the two studies reveals a number of disparities. The Louisville data, for example, show more pronounced effects at the ends of the semesters than do the Wellesley data. This may be due to differences in the academic calendars at the two schools, to the fact that Wellesley students were recalling events from only their 1 st year in college, or to other differences in methodology. The explanations that these investigators offer also differ, at least in emphasis, and we will discuss questions of interpretation in the following section. Nevertheless, both distributions are clearly nonuniform and suggest that memory for the year's autobiographical events has a strong seasonal component.

\section{Rationale and Overview}

Importance of the calendar effect. The lumpiness of students' memories across the year may provide clues to the structure of autobiographical memory and to its retrieval characteristics. It suggests that people's recall of their own lives is not only selective, but also patterned by the large-scale structure of their life roles. As we show later, these peaks occur even when we give no hint to students about school-related events or about the school schedule, suggesting that the school calendar provides a default method for storing or recalling personal occurrences. Natural methods of grouping such as this are of interest since they capture people's customary modes of dealing with information that is inherently multifaceted or diffuse. Just as chess masters' grouping of pieces in recall of board positions can tell us how they organize information about the game (Chase \& Simon, 1973), so grouping of autobiographical events in recall can tell us how people organize information about their own life history.

We note, too, that much of our knowledge of autobiographical memory currently comes from experiments in which subjects retrieve memories in response to arbitrary cues, usually consisting of single words (see Conway, 1990, for a review). Although these experiments have turned up some interesting leads, their results have often been contradictory (compare, e.g., Reiser, Black, \& Abelson, 1985, and Barsalou, 1988). In what follows, we show that the calendar effect is a robust phenomenon and, thus, capable of providing a sturdy base for theorizing about autobiographical memory. It therefore seems reasonable to take a closer look at the cause or causes of the calendar effect, and we proceed to do so in the experiments below.

Rival interpretations. One obstacle to understanding the Pillemer-Robinson findings is knowing whether the findings are due to the school terms (and their associated activities) or to other seasonal changes. The relatively large number of December memories in the Louisville data, for example, may be due to the Christmas season rather than to the end of the first semester. This issue is especially pressing since there is independent evidence that holidays may be a rich source of accessible autobiographical memories for students (Brewer, 1988). Other aspects of the distributions' shapes may be attributable to changes in activities caused by climate or by other nonschool factors. The Wellesley and Louisville schedules are quite similar, with semesters loosely coinciding with the fall and the winter/ spring seasons and with vacations mainly occurring in the period from Christmas to New Year's Day and in the summer. Thus, it is difficult to distinguish a calendar effect in these data from the effects of other seasonal variations.

Even if we assume that the school schedule is responsible for the effect, there is a second, related ambiguity. At both Louisville and Wellesley, the beginnings of school terms coincide with the ends of the major vacation periodsfirst semester starts after summer vacation and second semester after Christmas vacation. At other schools, however, vacations and semesters overlap; for example, Christmas vacation may occur before the end of the first semester. Thus, the recall differences could be due either to the official term boundaries (e.g., the change from first to second semester) or to the breaks that divide vacation from school activities (or both). In what follows, we will refer to these possibilities as effects of term boundaries and $v a-$ cation breaks. We intend our use of "calendar effect" to be neutral as to whether the effect is caused by term boundaries or vacation breaks, and we will use the term endpoint to denote both breaks and boundaries. 
Psychological mechanisms underlying the calendar effect. School boundaries or breaks could produce the recall peaks in several potential ways. One possibility is that activities near the beginning and the end of the school periods are more important or more salient for students. Although it is unlikely that more events happen at these periods, more important events might happen then. Events at the beginning or the end of semesters--such as arriving at college for the first time, being reunited with college friends after vacation, staying up all night studying for a final, handing in the last paper of the year, and attending graduation ceremonies - may all have special significance for students that would make these events more memorable than the more humdrum events that occur in the interior of the terms. But although there is evidence that personal importance is a mark of vivid memories (Rubin \& Kozin, 1984), the role of its importance in the calendar effect is unclear. Robinson (1986) asked the students in his freerecall experiment to classify the recalled events as very important, important, or unimportant. He found a significant positive correlation between rated importance and event frequency across months for one group of students, but only a weak negative correlation for a second group.

Another uncertainty about the calendar effect is that we do not know the true dates of the recalled activities. Both Pillemer et al. (1988; Pillemer et al., 1986) and Robinson (1986) obtained dates by asking students when the events occurred, and there is no guarantee that the dates were correct. This opens a second route to explaining the effect since it is possible that the students had a systematic bias to displace events toward the term boundaries. It is possible, in other words, that the recalled events actually happened uniformly throughout the year, and the recall peaks are due to students' erroneously dating the events too near the beginning or the end of the semesters. Such a tendency might be the result of the prominence of these time points. Students presumably have a good idea of the dates of the semester boundaries and may use these landmark dates when they have to determine the times of other events (Auriat, 1993; Loftus \& Marburger, 1983; Means, Nigram, Zarrow, Loftus, \& Donaldson, 1989). If they underestimate the temporal distance between the recalled events and the landmark, then more recalled events will appear near the extremes than near the middle of the terms. Underestimation of this sort would go along with evidence that people misjudge less salient objects as too close to more salient reference points (Rosch, 1975) or anchors (Tversky \& Kahneman, 1974). It is also consistent with evidence that extraneous events tend to be misremembered as occurring within major breaks of an ongoing sequence. For example, when subjects must recall the position of clicks that have been superimposed on speech, they often incorrectly locate the clicks at major boundaries of the sentences' phrase structure (Fodor, Bever, \& Garrett, 1974).

A third explanation of the data is that the beginnings and the ends of school periods function as retrieval cues, enhancing the recall of incidents in their vicinity. In attempting to recall events from the year, students may con- sider these endpoints and use them as prompts for further events. Thus, events associated with, and temporally close to, the endpoints will be overrepresented in recall. On this account, the events at the endpoints need not be more important than those from other times of the year, and the dates that students give them need not be biased. Instead, bias takes place in the way the students sample the events from long-term memory. This cuing hypothesis is quite similar to the explanation that Robinson (1986) advanced, and it also bears a resemblance to accounts of serial position effects in list learning that are based on retrieval from temporally distinctive items (see, e.g., Glenberg, 1987). Of course, the importance, date-bias, and cuing hypotheses just described are neither mutually exclusive nor exhaustive, but they are conceptually distinct and invite a closer look. We will consider other potential explanations in the General Discussion.

Overview of the experiments. In the experiments we report here, we examine the calendar effect, first, by trying to isolate it from other seasonal factors, and second, by investigating possible variables that might produce it. Our approach to isolating the effect takes advantage of differences in calendars from one school to another. In Experiment 1 , we chose two schools that have different academic schedules and asked students at these schools for their memories of events from the preceding year. If the distribution of such events depends on the school calendar, the resulting distributions should vary between schools. Since seasonal effects such as nonschool holidays and climatic changes are approximately constant at these schools, such effects cannot account for predicted shifts in the distributions. The remaining experiments take up competing hypotheses about the calendar effect. Experiment 2 pursues the date-bias and importance ideas by asking students to date campus events in which they participated and to rate these events for importance. Since the true dates of these events are known, the experiment provides a direct test of students' errors in dating. Experiment 3 explores the cuing hypothesis: To see whether memory distributions depend on explicit cues, we gave students calendars containing either the dates of the beginning and the end of school terms or the dates of holidays. The cuing hypothesis predicts realignment of the memory distributions when students recall events in response to these two calendars. The final experiment checks whether the calendar effect persists when students merely invent incidents that might have happened rather than retrieve actual events from longterm memory. It also examines the role of the events' distinctiveness.

\section{EXPERIMENT 1 Distribution of Recalled Events Across the College Calendar}

Although most colleges and universities in the United States have schedules that begin in the fall and end in the late spring, there are some variations in the academic calendars that can help us explore the calendar effect. If the 
peaks in the earlier studies were due to the school schedule, then differences in the schedule should change the peaks' positions. We therefore decided to study students from two schools that have quite different schedules. (We believe this is the first time such a direct comparison between calendar systems has been conducted.) One of the schools was the University of Chicago, which has a quarter system. Chicago's fall quarter begins at the end of September and finishes just before Christmas; its winter quarter starts after New Year's and finishes near the end of March; and its spring quarter begins about a week later and ends around the second week in June. The exact boundaries of the terms are shown in Figure 1 below.

We selected as a second school Cornell College in Mt. Vernon, Iowa, since it has an unusual nine-term calendar. School starts near the beginning of September, and there are four terms before Christmas, each about 1 month in length. Classes resume after a 2-week Christmas vacation, and there are five more month-long terms that continue until the end of May. (Figure 1 shows the position of the terms in more detail.) Students at Cornell take only a single course during each term. The student body and the school environments at Chicago and at Cornell obviously differ in ways other than those associated with their academic schedules, but none of these differences (to our knowledge) confound the predicted effects.

We asked undergraduates at both schools to describe 20 events that had happened to them during a single year and then to date these events. This procedure is similar to that of Robinson (1986) and of Pillemer et al. (1988; Pillemer et al., 1986), but the instructions do not explicitly mention the academic calendar and do not restrict students to events of the school year. On the basis of the earlier experiments, we expected to find a disproportionate number of events near the quarter breaks at Chicago. We anticipated a contrasting distribution at Cornell, although its shape should depend on the exact nature of the calendar effect: If the effect is due to term boundaries-for example, the shift from taking one course to taking another - then we should find the recalled events clustering at each of the Cornell breaks. If the effect is due to vacation breaks, however, we would not expect to find peaks between each term. Most of the terms at Cornell are separated by only a 4-day weekend, and the only appreciable vacations are during the summer and during Christmas. The vacation-school contrast should thus lead to more frequent events at the beginning and the end of the school year and around Christmas vacation.

\section{Method}

In February 1989 we asked undergraduates at both Cornell and Chicago to describe 20 personal experiences that had happened to them during the preceding year (i.e., in 1988). The students were to limit themselves to events that were less than 1 day in length, and they were to describe each event uniquely. They wrote these descriptions in a booklet, one event per page. After they finished their descriptions, we asked them to provide a date (month and day of the month) for each event.

Procedure. We gave each student a booklet containing instructions on its first two pages. The instructions asked the student to "recall some personal experiences that occurred sometime between the first day of 1988 and the last day of 1988 . These experiences should be things that actually happened to you, each of which occurred during a single day." The student was to describe each experience in one to five lines, "distinguishing each personal experience from all other personal experiences." Each of the 20 subsequent pages of the booklet contained five ruled lines for this purpose, along with a brief reminder of the instructions. We asked the student to pace himself/herself, spending about $1 \mathrm{~min}$ on each experience.

The experimenter read the instructions to students as they followed in their booklets. Students then proceeded on their own to record the 20 events. They were cautioned not to repeat experiences and not to turn back to earlier pages once they had completed a description. After the 20 description pages, the booklet had 2 pages with additional instructions. The first of these asked students to return to the description of the first event and to list the month in which it had occurred. They were then to continue writing the months of the events in the order that they had described them. Once they had finished giving the months of the events, they were to turn to the last instruction page, which asked the students to cycle through the events again and provide the date of the month (e.g., the 5th or the 14th) when the events had happened. (We separated the month and day tasks because some of the earlier experiments had asked for months only.) No prior warning had been given to students that they would have to date the events.

Participants. We tested 102 students (47 freshmen and 55 upperclassmen) at Cornell College, and 93 students ( 40 freshmen and 53 upperclassmen) at the University of Chicago. The same experimenter tested all students between February 15 and February 24, 1989. We had recruited the students through leaflets on the campuses and through advertisements in the student newspapers. Students took $30 \mathrm{~min}$ to $1 \mathrm{~h}$ to complete the booklets and received $\$ 5$ for participation.

\section{Results and Discussion}

The participants described a total of 3,900 events. A small number of these we discarded, however, because the student had not dated the event, had given the event a range of dates (e.g., May 10-13), or had described an event that must have taken place over more than 1 day (e.g., "vacationed in France"). We retained 3,828 events (98\% of the total), 1,836 from Chicago and 1,992 from Cornell. The retained events included items such as these:

1. I took a final in my law class in Harper. I was really nervous, but afterwards decided it was a really fun class.

2. K. and I went out to dinner at Sutliff (we both had deep fried shrimp), played pool; then we went into Cedar Rapids to see a movie.

3. I arrived in Chicago after driving all day and spent the night at Northwestern with J. and saw L.

We will consider the content of the events after discussing their quantitative properties.

Date distributions. Figure 1 plots the main results from this experiment, the frequency of the recalled events over the year. Many of the students were freshmen at the time of the experiment and therefore had been in college for only part of the period they were to recall (i.e., from September to December of 1988). For this reason, we segregated the data by year in school - freshmen versus upperclassmenas well as by college affiliation. From top to bottom in the figure, the panels show the results for Chicago freshmen, for Cornell freshmen, for Chicago upperclassmen, and for Cornell upperclassmen. The $x$-axis in each of these graphs is the week of the year from which the events were recalled: 
Week 1 corresponds to January 1-7, Week 2 to January $8-14$, and so on. ${ }^{2}$ The vertical lines in the figure indicate the position of the relevant school terms for each group of students. These positions are the official dates of the start and the end of terms, as given by the colleges' bulletins. The functional boundaries for individual students may of course differ from these official ones if they arrived at school early or left for vacation as soon as their exams were over.

The freshmen distributions have peaks near the beginning of the school year, the first time in college for these students. These peaks occur slightly before the term boundary, however, probably because students appeared on campus before the nominal beginning of the term. We will return to this offset when we look at the events' content. Notice that the peak at Cornell occurs about 3 weeks prior to the peak at Chicago, in line with the earlier starting date at Cornell (September 5 vs. September 26). These results accord with Pillemer et al.'s (1988; Pillemer et al., 1986) finding that the beginning of freshmen year produces a large number of autobiographical memories. A comparison of the graphs for freshmen and for upperclassmen in Figure 1 shows that the start of freshman year is more clearly marked than the start of later years in college, also in agreement with a trend in Pillemer et al. (1988; Pillemer et al., 1986). (See Fuhrman \& Wyer, 1988, for additional evidence that the distinction between a student's high school years and college years is temporally well marked.) We note that instructions in some of the earlier experiments asked students to "describe a memory you have of your freshman year in college," which could have primed events associated with the college calendar. Our instructions asked for the events of 1988; thus, the peaks at the beginning of school cannot be due solely to task demand and are robust over these differences in method.

The freshman distributions at both schools are also elevated in the last few weeks of the year, during the Christmas vacation period. This may be partly due to recency or to the Christmas holiday itself. Our instructions mentioned the first and last day of 1988, and this may also have increased the number of events recalled from these time points. However, the increase in events on the right of Figure 1 occurs earlier at Chicago, where the quarter ended on December 10, than at Cornell, which dismissed on December 21. The peaks at the beginning of school and at the beginning of Christmas are thus consistent with a calendar effect. There is no clear evidence, however, for an upturn in frequency at Cornell's other term boundaries. The change from one class to another was apparently not sufficient to produce a large number of recalled events, and this suggests that terms must be separated by a longer period of contrasting vacation activity in order to affect the distribution. We also note that the freshman distributions show an upturn around Week 23, possibly due to high school graduation.

The results from the upperclassmen echo the main trends in the freshmen data. For Chicago students, frequency peaks occur near the boundaries of all three academic quarters. In addition, there is an unexpected number of recalled events around Week 7. Since this point is about
1 year prior to the date of the experiment, it may represent "reinstatement" of the events for the same time of year (Pillemer et al., 1986). ${ }^{3}$ Valentine's Day also occurred in this week and may have had significance for some of our students (see Experiment 4 and the sample events in the General Discussion). No comparable effect appears in the data for Cornell upperclassmen, however, so the interpretation of this peak remains uncertain. The Cornell students recalled more events from the beginning and the end of the school year and around Christmas vacation than at other periods of the year. Once again, however, there is no clear sign that the remaining term boundaries-those that do not border Christmas or summer vacations-are associated with greater recall. 4

Do the recall distributions reflect school calendars? To evaluate the calendar effect in these data, we tabulated the number of recalled events that occurred near the boundaries at each of the two schools. For purposes of analysis, we counted an event as happening near a boundary if the date that the student assigned it was within 1 week of an official beginning or end of term. Thus, a particular event occurred near a Cornell boundary (only), near a Chicago boundary (only), near a boundary at both schools, or near neither school's boundaries. (The event would occur near both boundaries if, for example, it had a date of January 4, since both schools resumed classes then after Christmas vacation.) Because there are many more terms at Cornell than at Chicago, we would expect greater recall near Cornell boundaries due to chance alone. To equate the groups for the different number of terms, we calculated the number of events recalled per week when the week in question fell into one of the four categories just described. Table 1 displays these average number of events per week for Chicago and Cornell students. We again treated the freshmen and upperclassmen separately, counting freshmen events as near a boundary only if that boundary fell after the beginning of the school year, when these students first entered college. Most of the freshmen events occurred near neither of the colleges' boundaries for this reason.

The calendar effect implies that students should recall more events near the endpoints at their own school than near the endpoints at the other school. This difference appears in the first two columns of Table 1 for both freshmen and upperclassmen. Upperclassmen at Cornell are the obvious exception to this trend, recalling about the same number of events at Chicago boundaries as at Cornell boundaries. This is likely due to the fact that the Cornell boundary points include all the many internal term boundaries at that school, and we have already noticed in Figure 1 that Cornell subjects did not recall many events from these periods. We provide a further analysis of this group in the next section. The third column of Table 1 also shows that Chicago students tended to recall more events from the "both boundaries" periods than did Cornell students. This is probably the result of the fact that the boundaries that coincide were major ones at Chicago but usually minor ones at Cornell (i.e., school begins at Chicago about the time of the boundary between the first and the second terms at Cornell, as 


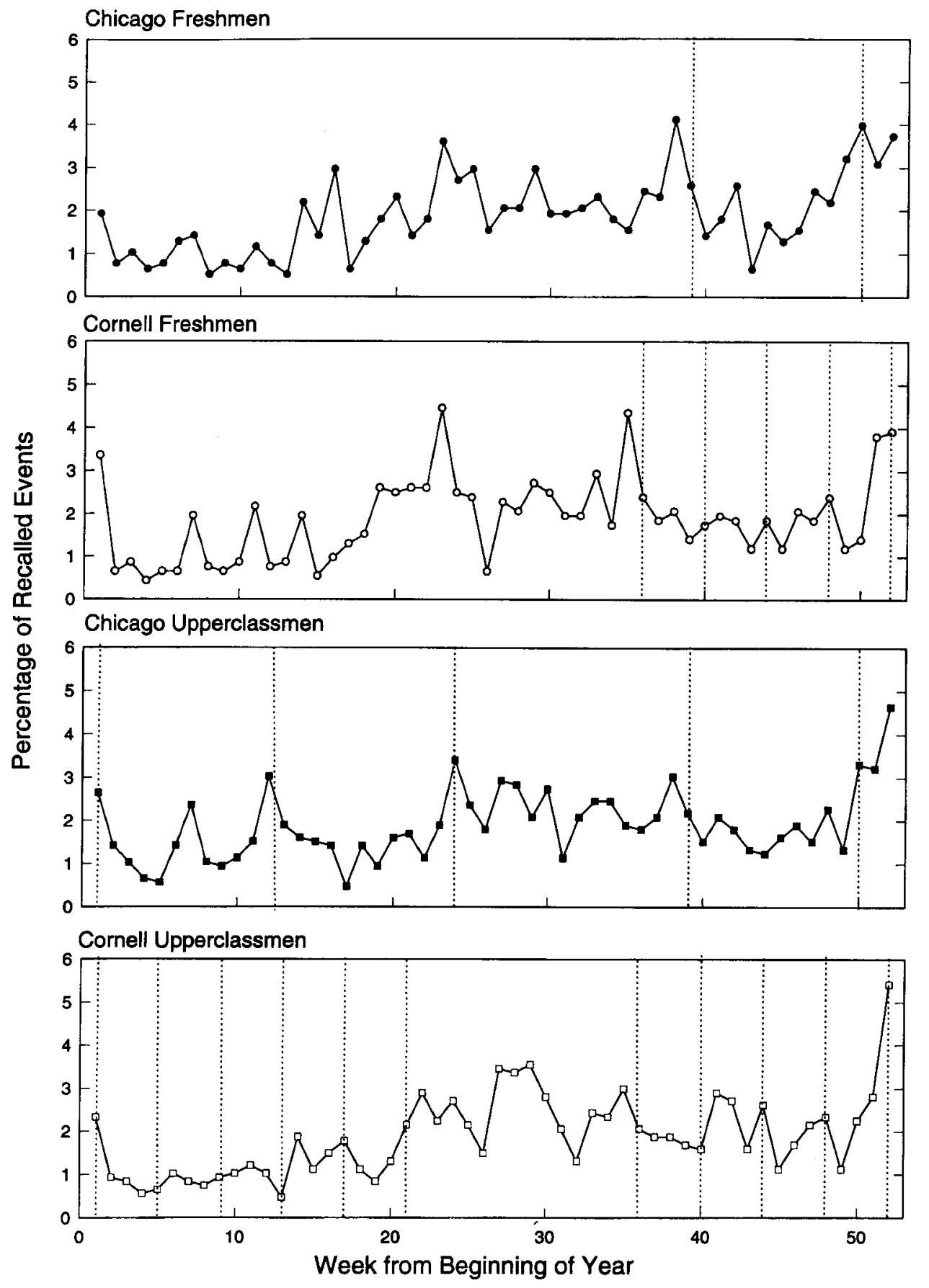

Figure 1. Percentage of recalled events by week for University of Chicago freshmen (top panel), Cornell College freshmen (second panel), Chicago upperclassmen (third panel), and Cornell upperclassmen (bottom panel). The $x$-axis shows weeks in 1988, beginning with January 1 . Vertical lines show the position of the term boundaries at Chicago and Cornell.

Figure 1 indicates). On the average, freshmen recalled $18.9 \%$ of their events near the boundaries of the school they attended and $11.5 \%$ of events near the boundaries of the school they did not attend. Upperclassmen recalled an average of $33.7 \%$ of events near the boundaries of their own school and $18.8 \%$ of events near the boundaries of the other school.
An analysis of variance (ANOVA) confirmed that the distribution of recalled items depends on the school. We analyzed the number of recalled events per week at Chicago boundaries, Cornell boundaries, and both boundaries, treating freshmen and upperclassmen in separate ANOVAs. Events recalled at neither boundary were omitted from the analysis since they add no further information. In both 
Table 1

Mean Number of Recalled Events Per Week for Weeks Occurring Near a Term Boundary at the University of Chicago and Cornell College (Experiment 1)

\begin{tabular}{|c|c|c|c|c|c|}
\hline \multirow[b]{2}{*}{ Group } & \multirow[b]{2}{*}{$n$} & \multicolumn{4}{|c|}{ Boundary } \\
\hline & & Chicago & Cornell & Both & Neither \\
\hline \multicolumn{6}{|l|}{ Freshmen } \\
\hline Chicago & 40 & 0.71 & 0.43 & 0.44 & 0.34 \\
\hline Cornell & 47 & 0.24 & 0.49 & 0.34 & 0.36 \\
\hline \multicolumn{6}{|c|}{ Upperclassmen } \\
\hline Chicago & 53 & 0.51 & 0.31 & 0.45 & 0.40 \\
\hline Cornell & 55 & 0.38 & 0.35 & 0.31 & 0.41 \\
\hline
\end{tabular}

analyses, the critical interaction between school and type of week was reliable $\left[F(2,170)=7.13, M S_{\mathrm{e}}=0.2291, p=\right.$ .001 , for freshmen, and $F(2,212)=3.68, M S_{\mathrm{e}}=0.0718$, $p=.03$, for upperclassmen].

Is the calendar effect due to term boundaries or to vacation breaks? Our inspection of Figure 1 suggested that not all of Cornell's many term boundaries affected recall. To get a clearer look at this difference, we can compare the number of events recalled from weeks adjacent to vacation breaks (beginning and end of summer and Christmas vacations) with those recalled from weeks adjacent to the remaining term boundaries (e.g., the boundary between Cornell's first and second terms). Cornell freshmen recalled an average of 0.74 events per week near vacation breaks, 0.33 events per week near more minor term boundaries, and 0.35 events per week for periods near neither endpoint. The difference between vacation breaks and other boundaries was significant $\left[F(1,46)=43.12, M S_{\mathrm{e}}=0.0919\right.$, $p<.001]$. For Cornell upperclassmen, recall rates were 0.48 events per week for vacation breaks, 0.28 for other term boundaries, and 0.41 for weeks near neither type of endpoint $\left[F(1,54)=23.19, M S_{\mathrm{e}}=0.4902, p<.001\right.$, for the difference between vacation breaks and other boundaries]. Recall rates were high for these students in nonboundary weeks because of the large number of events that came from the summer (Figure 1).

These data thus suggest that only those term boundaries that mark the border between school and vacation produced an increase in recall. It is possible, of course, that the large number of internal boundaries at Cornell decreased the importance of each of these endpoints. It is also an open question whether vacation breaks can affect recall on their own, since at Cornell and Chicago the beginnings and the ends of the main vacations were also term boundaries. ${ }^{5}$

Event content. The events students recalled ranged from those that were clearly associated with life at college, such as item 1 above, to those that had no obvious connection with school, as in item 2. It seems reasonable to suppose that school-related events would predominate around the times of the academic boundaries, whereas nonschool events might be relatively constant throughout the year or perhaps less frequent at endpoints. If so, then the calendar effect might be largely due to specifically school-related items. Support for this conjecture comes from Robinson (1986), who found that school events composed a larger percentage of recalled activities near at least some of the school boundaries than at other times of the year.

To see whether school events increased at boundaries for our own students, we classified all the events in our sample according to whether or not they were related to school. In doing so, we counted extracurricular events (e.g., sports events, music, or theatrical performances) as school related only if the student mentioned a school team or group. In some cases, we found that the events were connected with schools other than the one the student attended; examples are attending a social function at a different college, going to a younger friend's high school graduation, or visiting potential graduate schools. Item 3 is a sample event of this type. We therefore used a three-category scheme in which each event was classed as related to school, not related to school, or related to another school. Two judges independently classified the events in this way, agreeing on $88.9 \%$ of their decisions. Discrepancies were resolved by discussion. Figure 2 presents the mean number of recalled events per week for each of the three types of events. The graph divides the events into those in weeks adjacent to a term boundary and those in weeks not adjacent to a boundary, where the boundaries in question were the ones that the students had actually experienced (e.g., the boundaries at the end of September and the middle of December for Chicago freshmen).

Figure 2 shows that most recalled events were not related to school by our criteria. This is true for weeks adjacent to boundaries, as well as weeks not adjacent to boundaries, and agrees for the most part with Pillemer et al.'s (1988; Pillemer et al., 1986) and Robinson's (1986) findings. (In one of his experiments, Robinson found a majority of school-related events in January and May; in all other months, most events were not related to school.) For all four groups of students, however, the number of schoolrelated events increased at endpoints. On average, a student recalled 0.15 school-related events per week when the week bordered a boundary, but 0.04 school-related events per week when the week did not occur near a boundary. Nonschool events were more frequent near boundaries than at other times for Chicago students and Cornell freshmen, but less frequent near boundaries for Cornell upperclassmen. Over all four groups, 0.30 nonschool events per week were recalled near boundaries and 0.29 nonschool events per week at other times. Events concerning other schools were relatively infrequent and varied little from boundary to nonboundary periods. Thus, the increase in events at endpoints that we reported earlier is mainly, but not exclusively, due to school-related activities. Obviously, this conclusion depends to some extent on our criteria for classifying events as school related. These criteria were conservative, however. Relaxing them would increase the relative number of school events, but would shed little new light on the source of the calendar effect.

For both the freshmen and the upperclassmen, there was a reliable interaction of school relatedness and type of week $\left[F(2,170)=17.10, M S_{\mathrm{e}}=0.0239, p<.001\right.$, for freshmen, and $F(2,212)=19.86, M S_{\mathrm{e}}=0.0096, p<.001$, 


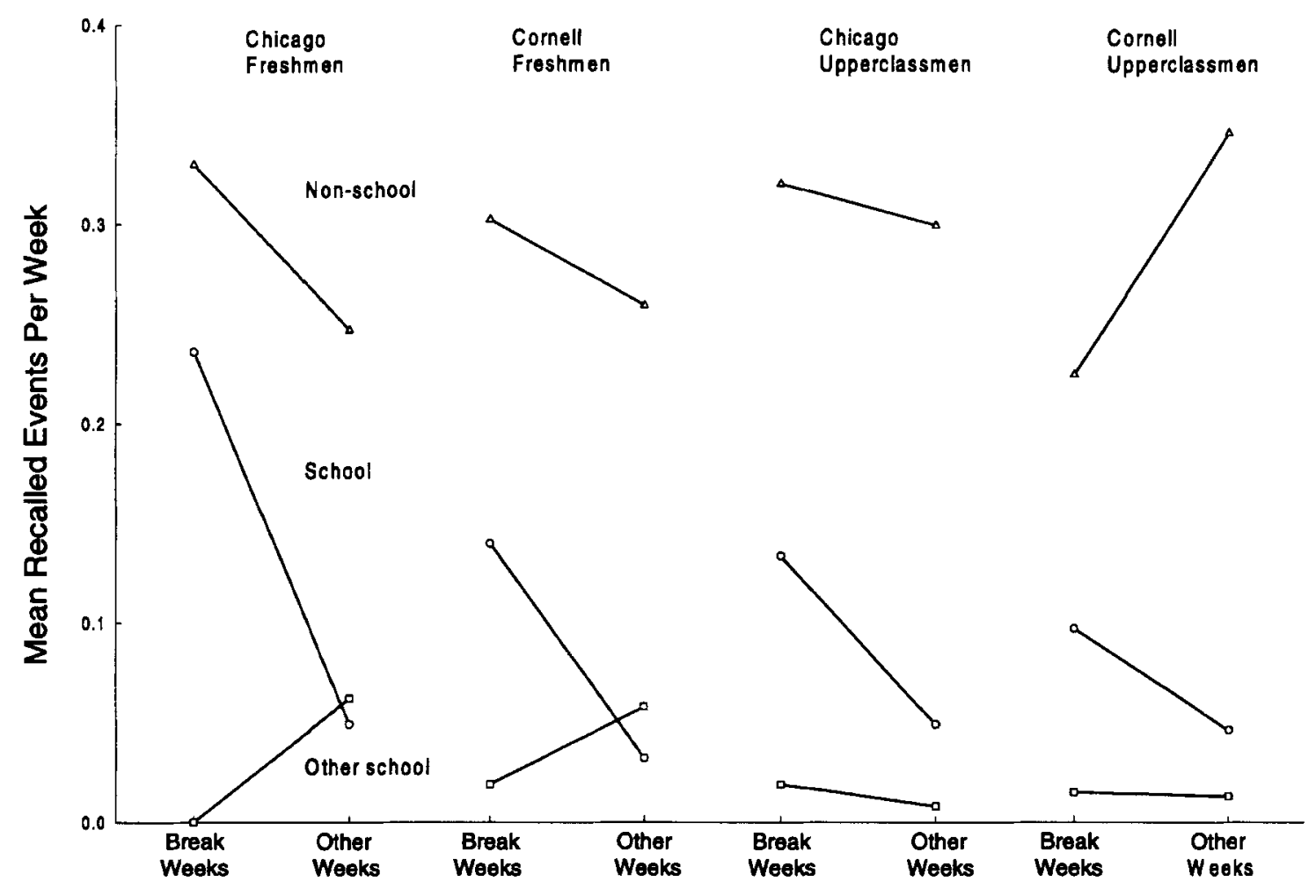

Figure 2. Mean number of events recalled per week by undergraduates at the University of Chicago and at Cornell College during weeks adjacent to term breaks and during all other weeks. Events are divided into school-related items $(O)$, nonschool items $(\Delta)$, and other-school items $(\square)$.

for upperclassmen]. The results for the upperclassmen also yielded a triple interaction of relatedness, type of week, and school $\left[F(2,212)=7.00, M S_{\mathrm{e}}=0.0096, p<.01\right]$. The latter effect may again be due to the large number of boundary weeks for Cornell upperclassmen: For these students, most of the nonboundary weeks occur in the summer, when events are usually not related to school.

The students' descriptions of events also throw light on why there are many recalled events in the week before the beginning of the school year (Figure 1). At this point, schoolrelated and nonschool events occur with approximately equal frequency ( $47 \%$ of events are school related, $49 \%$ are nonschool, and $4 \%$ are other school), despite the fact that classes had not yet begun. Most school-related events dealt with returning to campus, taking placement or graduate admission tests prior to classes, serving on orientation committees, or meeting old and new friends, as in the following examples:

4. While going to placement tests (math) during O-Week I met a person who loved to read, especially science fiction. He also liked Doctor Who and Blake's 7 . I was delighted to find someone with such similar interests.

5. Returned to Cornell with mixed feelings--"Senioritis"I was glad to see my friends but apprehensive about finishing up and not seeing everyone again the next year.
Nonschool events and other-school items were sometimes also indirectly related to the approaching school term (e.g., spending a day at the shopping mall for a new wardrobe for college) ${ }^{6}$

In general, the results from Chicago and Cornell strengthen the reasons for thinking that the calendar effect is indeed due to the school calendar and is not an artifact of nonschool conditions. Although the items that our students recalled were sometimes connected with seasonally recurrent happenings such as holidays, these nonschool events cannot explain the differences in the distributions of events that appear in Table 1. Neither can our instructions to list events that occurred within 1988. Moreover, specifically school-related events were responsible for most of the increase in recalled activities that occurred around the time of the term boundaries, just as one would predict if the school calendars were responsible for the frequency differences. Of course, we still need to ask about the psychological mechanisms that mediate the effect, since calendars are abstract entities that cannot by themselves cause students to recall more events from one period than another. (See Bourdieu, 1977, on the synoptic illusion - the tendency to view calendars as possessing an existence that is independent of human activities and modes of thinking about time.) We investigate these mechanisms in the remaining experiments. 


\section{EXPERIMENT 2 \\ Event Importance and Dating Accuracy in Relation to Calendar Endpoints}

In examining the events our students recalled in Experiment 1 , we took at face value the dates that the students gave them. The dates students produced were the ones we used in constructing the distributions of events in Figure 1 and in determining whether the events occurred near endpoints. There is reason for skepticism, however, about the accuracy of these dates, since one of the clearest generalizations that has emerged from the study of autobiographical memory is that students rarely remember the exact calendar date of personal events (e.g., Baddeley, Lewis, \& NimmoSmith, 1978; Linton, 1975; Means et al., 1989; Rubin \& Baddeley, 1989; Strube \& Neubauer, 1988; Thompson, Skowronski, Larsen, \& Betz, 1996; Wagenaar, 1986). For example, Linton (1975) found that the average absolute error (i.e., |true date - estimated date|) in dating personal events from her own life was 12 days for episodes occurring 4-8 months prior to test. Errors in dating are one possible source of the calendar effect, as we noted earlier (see Rationale and Overview). If students mistakenly shift the time of the remembered events toward term boundaries or vacation breaks, then these endpoint periods will appear overpopulated compared with periods in the interior of the term.

To determine whether biased dates are causing the calendar phenomenon, however, we need to know the true time of the events. The strategy of the present study is to use campus events, such as specific athletic events, movies, and concerts, in which students participated and for which the true dates are known (see Huttenlocher, Hedges, \& Prohaska, 1988, and Rubin \& Baddeley, 1989, for similar procedures). We gave students a long list of such events and asked them to indicate which of the events they had personally engaged in. Students then dated this subset of events and rated them for their importance. If students tend to distort the events toward school endpoints, we would expect their estimated dates to fall between the true date and the nearest calendar endpoint. (We conducted this experiment at the University of Chicago, where term boundaries and vacation breaks converge.)

This date-bias prediction contrasts with those of alternative explanations of the calendar effect. For example, students in earlier experiments may be recalling more events at school endpoints because more important events happen at that time or because endpoints act as cues for recall of associated events, as we described earlier. If either alternative is right, there is no reason to expect students to date events too close to endpoints.

The present experiment did not include a direct test of the cuing hypothesis, and we will get back to it in Experiment 3, but the importance theory does have implications in the present context. In order to assess the importance hypothesis, we asked students to rate the personal importance of each event they participated in. If important incidents tend to cluster at the endpoints, average importance ratings should be greater at those times than at points in the middle of a term.

\section{Method}

Students in this experiment received a booklet containing a randomized list of 235 descriptions of events that happened at the University of Chicago in 1993. The events included B52's Concert with Juliana Hatfield; Law School Films: Star TrekIV: The Voyage Home; Works of the Mind Lecture: "On Darwin: The Origin of The Origin of Species"; and Women's Basketball: Maroons versus CarnegieMellon. We told students that all events happened during 1993, and for each event we asked them to indicate (by circling "yes" or "no" in their booklets) whether they had participated in it. (For athletic events, plays, etc., students were to respond "yes" if they had been a spectator or performer, but to respond "no" if they merely knew of the event but did not attend.) After the students had indicated their participation in all events, we asked them to return to the beginning of the booklet and to write the month and day of the month (e.g., March 29) for each event they had marked "yes." Finally, we instructed them to start at the beginning once more and to rate each "yes" event for "how important the event was to you." We stressed the personal importance of the events since personal rather than the historical importance seemed more likely to affect students' ability to recall the items. Students indicated their rating on a 11-point scale $(0=$ not at all important $; 10=$ couldn't be more important $)$. (We consider other interpretations of importance in Experiment 4.)

We selected the events from those listed in the University of Chicago Chronicle, which publishes a biweekly calendar of activities sponsored by university organizations. We eliminated all events that occurred on more than 1 day (e.g., plays with more than one performance) and those whose description contained clues to their exact time of occurrence (e.g., a Halloween party). Because of our interest in students' dating errors, we also attempted to space the events uniformly throughout the year, giving preference to events that undergraduates were likely to attend. We chose five events from each week in 1993, except for 6 summer weeks and 2 weeks during Christmas vacation when the calendar listed too few events to complete our sample. (In terms of Figure 3, below, the exceptions were Weeks 24, $25,36,37,38,39,51$, and 52 . These weeks contained $1,4,2,1,2,3$, 2 , and 0 events, respectively.) The final set of events was randomized in a new order for presentation to each of the students.

We tested students during February 1994, so the interval between the end of the target year (1993) and the experimental session was approximately the same as in Experiment 1 . Students in the study were 50 upperclassmen ( 2 nd -4 th year students) enrolled at Chicago. Three students indicated that they had not participated in any of the events during the school terms, and a 4th student received a booklet whose pages were incorrectly ordered. Data from the remaining students appear in the analyses that follow. We tested the students in two groups of 20 and 30 individuals. The length of the session varied since students had taken part in different numbers of events, but all finished within $40 \mathrm{~min}$. We had recruited the students by means of posters on campus and paid them $\$ 6$ for participating.

\section{Results and Discussion}

Students in this experiment participated in an average of 10.6 of the campus events, with the number varying from 1 to 40 across students. Since few undergraduates are on campus during the summer, there were relatively few events from the summer weeks that our students recognized, and we therefore omit these items from our discussion of the data. In examining the results, we first consider evidence that relates to the date-bias hypothesis and then evidence for the importance hypothesis. 
Bias in dating. Suppose that the date-bias hypothesis is correct and that students displace events toward the nearest calendar endpoint. We would then predict that students would give events that actually occurred just before an endpoint too recent a date (i.e., would telescope the event forward in time), whereas they would give events that occurred just after an endpoint too early a date (i.e., would telescope the event backward). To examine this prediction, we calculated the signed error for each event, defined as the date that the student gave the event minus its true date. For example, if a student dated an event December 18 , but the event had actually taken place on December 21 , the signed error would be -3 days (i.e., $18-$ 21). Thus, positive signed error indicates that the event had too recent a date at test, and negative signed error indicates that the event had too early a date. The top panel in Figure 3 plots this signed error measure across the weeks of the target year, with the relevant school endpoints shown as dashed reference lines. If students are moving events toward the nearest endpoint (in accord with the date-bias hypothesis), then signed error will be negative over approximately the first half of a term (as students should be telescoping backward toward the previous endpoint) and will be positive over the second half (as students should be telescoping forward to the next endpoint). Inspection of the figure turns up little evidence for such an effect. Instead, signed error tends to be greater at the beginning of a term, declining toward the end. This trend is more in line with the possibility that students are displacing events toward the middle of the terms rather than toward the endpoints. The exact crossover point-where signed error changes from positive to negative - is difficult to determine, however, because of the paucity of summer events.

As a simple test of dating bias, we can compare the distance between the nearest endpoint and an event's true date with the distance between the endpoint and the date subjects gave the event. Let the true distance of an event be the distance between the event's true date and its nearest endpoint (|true date - nearest endpoint to true date|), and let the subjective distance be the distance between the subjective date and the same nearest endpoint (|subjective date - nearest endpoint to true date|). If the date-bias hypothesis is true, then the subjective distance should be smaller than the true distance. In fact, the data are resoundingly in the opposite direction, with the mean true distance being 19.5 days and the mean subjective distance being 65.9 days. For 42 students, the subjective distance was larger than the true distance, for 3 students true distance was larger than subjective, and for 1 student they were equal $(p<.001$ by a sign test).

Of course, even though students are not moving events toward the nearest endpoint, they may be moving them toward some endpoint or other, and this too could lead students to report a larger number of items from endpoint than from non-endpoint periods. To see whether this is possible, we can redefine subjective distance as the distance between the subjective date of an event and the nearest endpoint $t o$ that subjective date. If subjective dates are nearer endpoints than true dates, then our redefined subjective distance should be smaller than true distance. But again the data provide no support for this hypothesis. The mean of the new subjective distance is 20.2 days, about the same as the mean true distance of 19.5 days that we just reported. Subjective distance is larger than true distance for 25 of our students, smaller for 21 . It is still conceivable that students displace events toward endpoints when they date recalled events (as in Experiment 1) but not when they date recognized events (as in the present experiment); however, we know of no theoretical or empirical reason to expect such a difference.

These results, of course, do not mean that students' dates were unbiased. It is evident from Figure 3 that students tended to give the more remote events (i.e., those from winter and spring quarters) dates that were too recent and the later events (those from fall quarter) dates that were too early. This effect holds, too, in many earlier studies of memory for the time of occurrences (see Friedman, 1993, for a review). A likely explanation is that when students are uncertain about the time of an event, they assign it a date from the middle of the experimental range as a guessing strategy. (Recall that students knew that all of the events occurred in 1993.) This effect may also be related to students' tendency to avoid the extreme values of a rating scale, sometimes called "response contraction bias" (Poulton, 1989).

A microvariation on the same guessing or responsecontraction strategy may help explain why subjective distance was greater than true distance in the first of our tests. If students retain some memory of the term in which an event happened, but not the exact date of the event, they may locate the event near the middle of the term in question and away from the endpoints (see Huttenlocher et al., 1988). This type of bias, however, is not helpful in explaining the calendar effect, for reasons we take up in the General Discussion.

Importance. The importance hypothesis predicts that events occurring near the beginning and the end of terms will be rated as more important than other events. Our students rated the importance of each event in which they participated, so we should find an increase in their ratings near the school endpoints if the hypothesis is correct.

The mean importance ratings on the 0-10 scale appear in the bottom panel of Figure 3, and they give little indication that more important school events occurred near the endpoints. Twenty-two of the students had participated both in events that occurred within a week of an endpoint and in events that occurred in non-endpoint weeks. For these students, mean importance for endpoint events was 5.44 and mean importance for non-endpoint events was 5.00. This trend is in the direction that the importance hypothesis predicts but is not reliable $\left[F(1,21)=0.76, M S_{\mathrm{e}}=\right.$ $2.823, p=.39]$. We acknowledge, of course, that subjects may provide different importance ratings for events that 

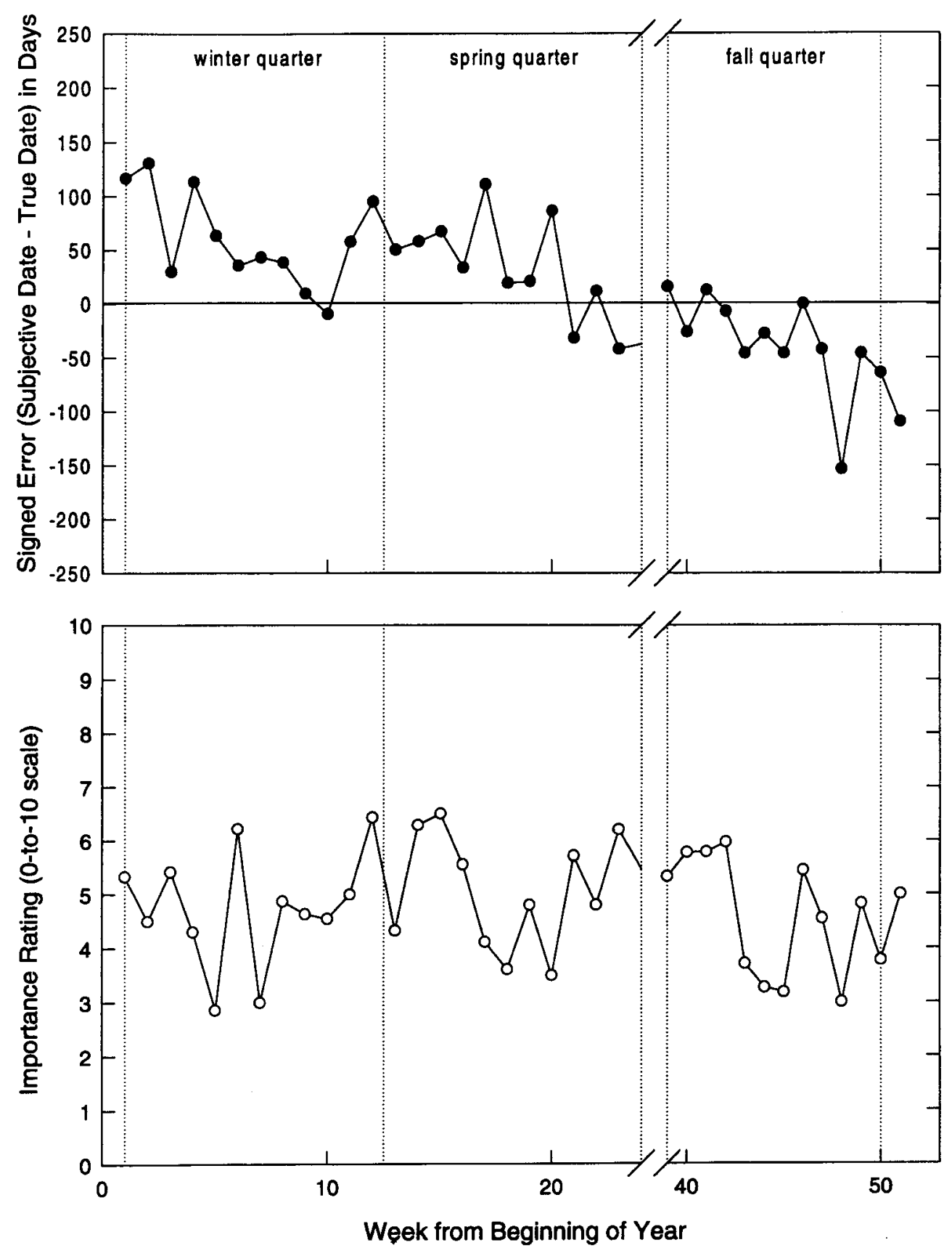

Figure 3. Signed error of dates by week (top panel) and mean importance ratings (bottom panel) for termtime events (Experiment 2). The $x$-axes show weeks in 1993, beginning with January 1 . Vertical lines indicate (from left to right) the positions of beginning of winter quarter, end of winter quarter/beginning of spring quarter, end of spring quarter, beginning of fall quarter, and end of fall quarter at the University of Chicago.

we selected than for events that they recall, and we will examine rated importance for recalled events in Experiments 3 and 4 .

Further implications. The date-bias and importance hypotheses do not fare well with the data of the present experiment. Although students' dates were biased, especially for the earliest and latest events, the direction of bias was generally opposite that of the predictions. The rated importance of the events correlated weakly at best with the ends of the school terms.

It is possible to object that the type of events that we employed in this experiment differs from the type students recalled in Experiment 1, and so may have little bearing on the calendar effect. Even though the students had participated in them, the campus events that we selected from the university calendar may not be representative of the 
personal events that produce the calendar effect. Thus, the failure to find evidence for the date-bias or the importance hypothesis in the present experiment does not necessarily mean that these factors play no role in increasing the frequency of endpoint events in free recall. Although there may be some truth to this objection, there are nevertheless two considerations that weigh against it. First, we showed earlier that the calendar effect depends largely on an increase of school-related events at the endpoints. Since the events of the present experiment are clearly school related, the temporal distribution and importance of these items should be relevant to the calendar effect.

A second reason for thinking that the data from the current set of events bear on the calendar effect comes from a pilot experiment that we conducted at two Chicago high schools. The pilot study consisted of a series of six sessions, about 3 weeks apart, which overlapped some of the academic endpoints. In each of the first five sessions, the students described a series of school-related personal events and nonschool-related personal events that had happened to them during the last 2 weeks. They also dated these events and rated them for importance. In the final session, we conducted an incidental test of the events they had described earlier. We gave students personalized booklets with verbatim copies of their own earlier event descriptions and had them redate and rerate the items. We assumed that students' original dates for the events would be more accurate than the dates they gave during the final test, because memory for time of occurrence decays with the length of the retention interval (Baddeley et al., 1978; Linton, 1975; Means et al., 1989; Rubin \& Baddeley, 1989; Strube \& Neubauer, 1988; Thompson et al., 1996). Thus, if the date-bias explanation is correct, the final dates should be displaced toward the endpoints relative to the original dates. There was no detectable effect of this sort, however, for either school-related or non-school-related personal events (though the results did show the bunching of events toward the middle of the experimental range of dates that we observed in Figure 3). Thompson et al. (1996, chap. 7) reported some related findings. ${ }^{7}$ Similarly, the importance ratings, both in the initial and the final sessions, were essentially flat across the school calendars.

These pilot data are consistent with the present results in suggesting that students do not displace events toward calendar endpoints and do not think of endpoint events as more important than events that occur at other times. However, we still need to look at the third, cuing, explanation of the calendar effect that we proposed earlier. Even though endpoints do not attract events or enhance their importance, they may nonetheless aid in retrieving events that occur in their neighborhood. We now turn to a test of this hypothesis.

\section{EXPERIMENT 3 \\ Cued Recall With Holidays Versus School Landmarks}

In this experiment, we consider the possibility that the calendar effect is a retrieval phenomenon. According to this hypothesis, the divisions between vacation and term time provide students with entry points into their memories of the year, allowing them to recall associated incidents. Because the related incidents will tend to be school events that happened at about the same time, students recall more events at these endpoints than at other points during the year. The school calendar may be an especially potent source of cues since it delimits broad changes in students' vacation versus school activities, as we mentioned earlier. School endpoints, however, may not be the only possible route into autobiographical memory. Other types of cues may also make contact with the year's events, and if so, the cuing hypothesis predicts that response frequency will shift with the temporal position of these alternatives. The alternative cues should produce recall functions that differ from those observed in Figure 1.

To examine the cuing hypothesis, we gave one group of students calendars that indicated the dates of the school endpoints, and we gave a second group calendars that showed the dates of holidays (e.g., Independence Day and Valentine's Day) from other parts of the year. Students in both groups were to record personal experiences on the calendar, but they were not told to use the indicated school or holiday dates. If the holidays act as memory prompts, however, we should expect the holiday group to recall more events from around the time of these holidays (and fewer events from term boundaries) than students of the school group. (Students may ignore the holiday cues or substitute their own cues for the ones we present, but if so, the distributions should exhibit no peaks at holidays.)

As a further test of the importance hypothesis, we also asked students at the end of the study to rate the importance of all the experiences they had described. Because this hypothesis claims that more important events occur near school endpoints, it predicts that both groups should give higher importance ratings to events near these endpoints.

\section{Method}

As in Experiment 1, students in this experiment tried to recall unique personal experiences that had happened to them during the previous year. The procedure was similar to that of the earlier experiment, the major change being the format of the students' booklets After the instruction pages, a booklet contained 12 answer pages, 1 for each month of the year. An answer page displayed the month at the top (e.g., "November 1991") and had a list of the days of that month (in order) in a column on the left side of the page. The days were listed in the following form: November 1 (Friday), November 2 (Saturday),

.. November 30 (Saturday). At the right of each day was a long blank line for students to describe their experiences. Students in the school group saw labels marking the start and the end of the three quarters. January 7 was marked "Beginning of Winter Quarter"; March 23, "End of Winter Quarter"; April 1, "Beginning of Spring Quarter"; June 15, "End of Spring Quarter"; September 30, "Beginning of Fall Quarter"; and December 14, "End of Fall Quarter." Students in the holiday group saw labels for the positions of six holidays: February 14 was marked "Valentine's Day"; May 12, "Mothers' Day"; May 27, "Memorial Day"; July 4, "Independence Day"; October 31, "Halloween"; and November 28, "Thanksgiving Day." We had chosen these six holidays to equate the number of labeled days in the two booklet types, while avoiding holidays that occurred near the time of the school boundaries (e.g., Christmas and New Year's Day). 
Table 2

Percentage of Recalled Events and Rated Importance for Items Occurring Near a Term Boundary and Near a Holiday (Experiment 3)

\begin{tabular}{|c|c|c|c|c|c|}
\hline \multirow[b]{2}{*}{ Group } & \multirow[b]{2}{*}{$n$} & \multicolumn{4}{|c|}{ Position of Event } \\
\hline & & Term Boundary & Holiday & Both & Neither \\
\hline \multicolumn{6}{|c|}{ Percentage of Events Recalled } \\
\hline School & 25 & 36.2 & 18.3 & - & 45.4 \\
\hline Holiday & 25 & 27.8 & 26.6 & - & 45.6 \\
\hline \multicolumn{6}{|c|}{ Mean Importance Rating ( $0-10$ scale) } \\
\hline School & 25 & 4.71 & 5.15 & - & 5.23 \\
\hline Holiday & 25 & 5.33 & 5.59 & - & 6.07 \\
\hline
\end{tabular}

We asked students to proceed through the booklet, describing the experiences from 1 month before turning to the next. The order of the months was random for each student, and there was no limit to the number of events the student could describe. The instructions did not mention the holiday or school labels. After the students had recorded events for all the months, we asked them to return to the first event and rate its importance on a $0-10$ scale $(0=$ completely insignificant; $10=$ extremely important $)$. They then rated the events in the order they had first described them.

We conducted the experiment during February and March 1992 and asked students for events of 1991. Thus, the elapsed time between the end of the target year and the test session was similar to that in Experiments 1-2. Fifty University of Chicago upperclassmen participated in this experiment, 25 in each group. Each student received $\$ 5$ at the end of the session.

\section{Results and Discussion}

Students in the school group produced a mean of 43.2 events, and students in the holiday group produced 49.1. Although we asked for unique events, students occasionally repeated a description or reported an event that was obviously not unique, and we will omit these items ( $7 \%$ of the total) in what follows. We look first at the distribution of the events and then at the ratings of importance for the same items.

Event dates. The top panel of Figure 4 shows the average percentage of events that students in the school group produced from each week in 1991. The results show a clear calendar effect with peaks at the academic endpoints (solid vertical lines). This distribution should be compared with that in the third panel of Figure 1, which comes from a comparable group of students who did not have explicit cues. The overall shape of the distributions is obviously similar, with the endpoints somewhat more clearly marked in Figure 4. This is what we would expect if some proportion of students in the earlier experiment had used school endpoints as implicit cues. By contrast, the holiday group (bottom panel of Figure 4) produced more events from around the cued holidays (dashed lines) and fewer events at the school endpoints. School calendar effects are still noticeable for this group, however, especially at the end of the school year in Week 24. Likewise, some of the minor peaks for the school group may reflect effects of holidays (especially Valentine's Day, Independence Day, and Thanksgiving). In sum, it appears that school cues sustained or increased the effect of the school calendar, whereas the alternative holiday cues decreased this effect.
To substantiate this difference between the school and holiday groups, we computed the percentage of events that fell within 1 week of the holidays and the school endpoints that had appeared in the booklets. These figures appear in the top half of Table 2. (We chose the holidays so as not to coincide with the school endpoints, so no event occurred near both a holiday and an endpoint.) As Table 2 shows, the proportion of events at term boundaries was higher for the school group than for the holiday group, whereas the proportion of events near holidays was greater for the holiday group than for the school group. We performed an ANOVA on the raw number of events recalled by the two groups for each of the three intervals. (Recall that there was no limit on the number of events that the students could report in this experiment, so a larger number of events near, e.g., the school endpoints, does not entail a smaller number of events for the remaining periods.) This analysis produced a reliable interaction between group and interval $\left[F(2,96)=4.28, M S_{\mathrm{e}}=25.60, p=.02\right]$. These data indicate that explicit prompts can alter the calendar effect: Holiday prompts clearly diminished students' tendency to retrieve incidents around school endpoints while increasing events near the holidays.

Importance. Students' ratings of importance agreed with the evidence from Experiment 2 that events near school endpoints are no more important than events that occur elsewhere in the year. The bottom half of Table 2 reports mean importance for events near the critical school and holiday dates and for events near neither of these dates. Across the two groups, importance ratings averaged 5.02 for incidents near school endpoints, 5.37 for incidents near holidays, and 5.65 for all other incidents. This difference was a significant one $\left[F(2,96)=5.08, M S_{\mathrm{e}}=0.9934\right.$, $p=.008]$ and was in the direction opposite that predicted by the importance hypothesis. The ratings also exhibited a marginal effect of group, with holiday subjects giving slightly higher ratings than school subjects $[F(1,48)=3.22$, $\left.M S_{\mathrm{e}}=4.7254, p=.08\right]$. There was no interaction, however, between group and event location $[F(2,96)=0.49$, $\left.M S_{\mathrm{e}}=0.9934\right]$.

As Table 2 suggests, there was also no significant correlation between rated importance and the number of events retrieved across the weeks of the year. For both groups of students, the correlation between these variables was small and slightly negative: $r(50)=-.08$ for the school group and -.14 for the holiday group ( $p>.10$ in both cases).

\section{EXPERIMENT 4 \\ Distinctiveness of Events and of Pseudo-Events}

Students in Experiments 2 and 3 rated events in terms of their personal importance, since we initially thought that this variable was likely to produce the calendar effect. As it happened, however, neither experiment provided much support for the importance hypothesis, and this may mean that we focused on the wrong variety of importance. Perhaps what matters for the calendar effect is the distinctiveness of the recalled events, rather than their personal sig- 
School Group

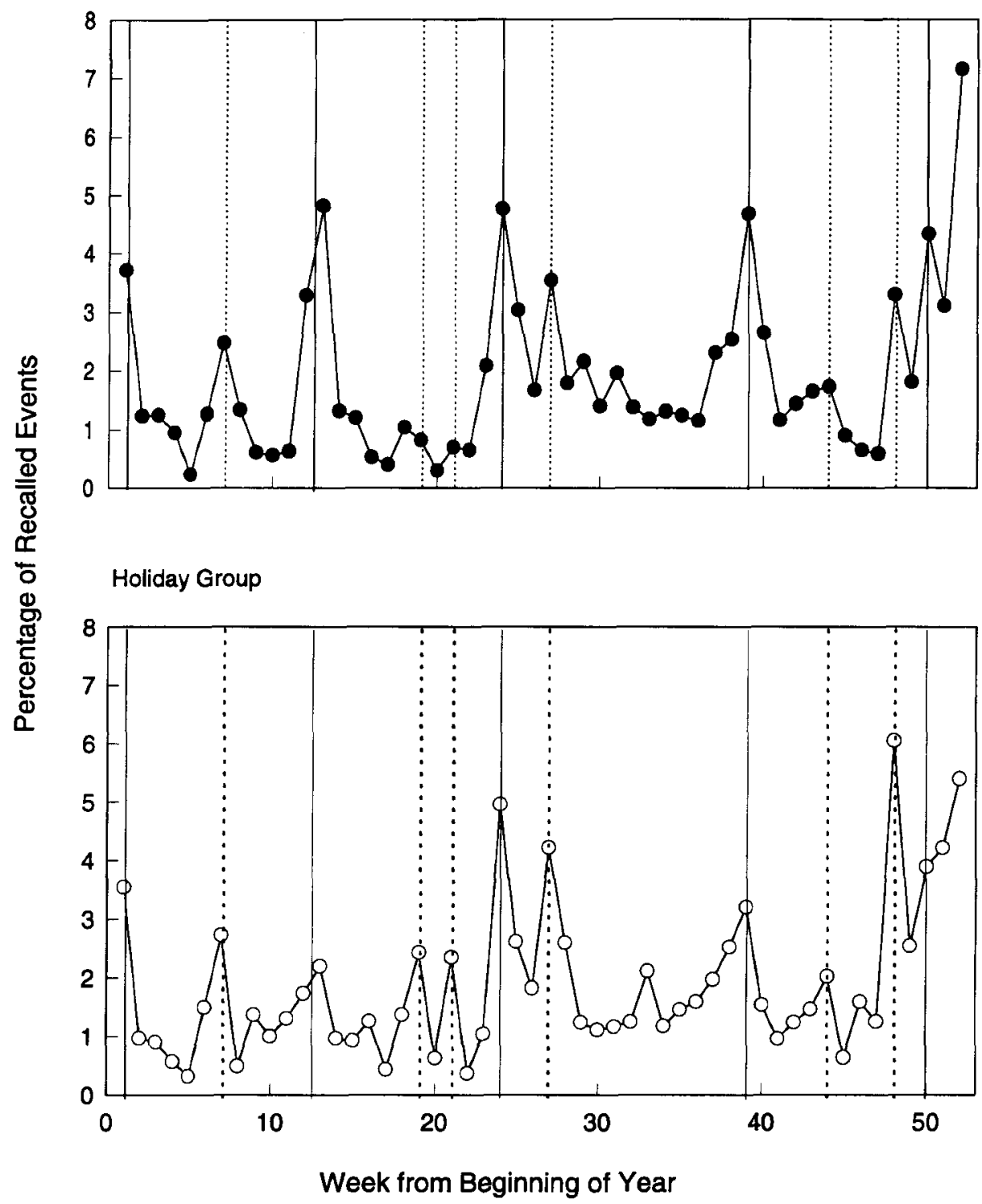

Figure 4. Percentage of recalled events by weeks for the school group (top panel) and the holiday group (bottom panel). The $x$-axes show weeks in 1991, beginning with January 1 . Solid vertical lines indicate (from left to right) the positions of beginning of winter quarter, end of winter quarter/beginning of spring quarter, end of spring quarter, beginning of fall quarter, and end of fall quarter. Dashed vertical lines show positions of Valentine's Day, Mother's Day, Memorial Day, Independence Day, Halloween, and Thanksgiving.

nificance. An informal look at the events that students in Experiment 3 rated very important suggests that these were changes in personal relationships or family emergencies. The school-related events that helped produce the calendar effect, by contrast, do not appear personally important in this way, but they may yet be distinctive when compared with other events of the year. For this reason, we asked students in the present experiment to rate distinctiveness rather than personal import.
This experiment also addressed a residual question about school endpoints. We assume that these endpoints are useful to students because they provide access to events that actually occurred during the year. If the students do not have to search for or to retrieve personal events but are free to fabricate events that might have happened, there should be no pressure to employ the endpoints and, hence, no calendar effect for these pseudo-events. We examined this possibility in the present experiment by asking one 
group of students (the pseudo-event group) to generate events that might have happened in the last year to someone in the same introductory psychology class, someone with whom they were not personally acquainted. A second group of students (the event group) performed the standard event-retrieval task.

It was possible, of course, for the pseudo-event group to use the academic calendar to aid them in constructing events that might have happened to their classmates. However, this group did not have to worry about producing events that actually occurred in a specific time frame. Although the events were supposed to be ones that could have happened in the previous year, there was no real need for these students to tailor the events to this interval. In addition, the pseudo-event group did not have to retrieve events, but could generate them from common activities that college students engage in (e.g., attending parties, going to football games). For these reasons, the pseudo-event students did not have to think about the academic calendar, and their event distributions should be much flatter than those of the event group.

\section{Method}

The participants in this experiment completed a 2-page booklet that asked them to describe five events, to date each of these events, and to rate them for distinctiveness. For students in the event group, the $1 \mathrm{st}$ page contained the usual instructions to describe five events that had happened to them in the previous year (1994) and to write these descriptions on the bottom of the same page. (The page contained blank lines labeled "Event 1," "Event 2," and so on, for this purpose.) For students in the pseudo-event group, the instructions asked them to think about some person in the same class with whom they were not acquainted and to describe five events that might have happened to that person during 1994. All participants were then to turn to the 2nd page of the booklet, which asked them to write down the date on which each event was most likely to have occurred and to rate the distinctiveness of each event on a $0-10$ scale. The instructions defined "distinctiveness" as "how different or unusual an event is for a person."

The experiment was conducted as part of group-testing sessions in two introductory psychology courses during the winter quarter of 1995 at Northwestern University. Both testing sessions occurred during a class period in the lst week of the courses (at the beginning of January 1995). The two types of booklets were randomly distributed to the students and were interleaved with a variety of unrelated screening and testing materials. (We were restricted by conditions of the group test to asking for 5 events per student rather than the 20 we elicited in Experiment 1.) Most of the students in the course were freshmen, and we report only the freshmen data here. There were 108 freshmen in the event group and 97 in the pseudo-event group.

\section{Results}

Freshmen reporting events they experienced produced the usual calendar effect, with more events recalled near the beginning of the school year and at Christmas vacation. The top panel in Figure 5 shows that these students also reported many events from Week 23 (June 3-9), which may well mark graduation from high school and the beginning of summer vacation. By contrast, the distribution for students reporting events that might have happened to another member of their class contains no clear peaks (see Figure 5 , bottom panel). Although there is a suggestion of an upturn near Christmas vacation for this pseudo-event group, there appear to be no trends of the sort that the event group generated.

The event group reported significantly more events for weeks that bordered school endpoints than for other weeks $\left[F(1,203)=9.98, M S_{\mathrm{e}}=0.0176, p<.01\right]$. This difference appears in Table 3, which also shows that the pseudo-event group recalled about the same number of events for the two types of weeks $[F(1,203)=0.14$, using the same pooled error term]. The interaction between group and type of week was only marginally significant, however $[F(1,203)=$ $3.52, p=.06]$. A look at the event descriptions suggests that students in the pseudo-event group often made up simple, script-like items, such as going out on a date, that did not require special knowledge of events from the past year (Schank \& Abelson, 1977). Since there was no need for these subjects to search episodic memory for such events, there would have been no pressure to use endpoint cues to access these imagined items.

Table 3 also provides information about the effect of distinctiveness. There were 52 students in the event group and 32 students in the pseudo-event group who rated the distinctiveness of at least one event from an endpoint week and one event from a non-endpoint week. As might be expected, these students gave higher distinctiveness ratings when dealing with their own events $(6.28$ on the 10-point scale) than when dealing with possible events of others $\left[4.94 ; F(1,82)=8.73, M S_{\mathrm{e}}=8.1473, p<.01\right]$. There was no sign, however, that events occurring near term boundaries are more distinctive than events at other times of the year. Neither the main effect nor the simple main effects of type of week was significant for these students (all $F_{\mathrm{s}}<1, M S_{\mathrm{e}}=4.6459$ ). The interaction between group and type of week was also nonsignificant $[F(1,82)=0.32$, $\left.M S_{\mathrm{e}}=4.6459\right]$. Thus, distinctiveness proves no better than personal importance in distinguishing endpoint events from other events. It remains an open question, however, whether other definitions of distinctiveness could do better. Perhaps if we had asked subjects for distinctiveness in terms of rate of contextual change, we might have been able to detect a difference between endpoint and non-endpoint weeks. Nonetheless, we have been unable, so far, to find consistent effects of distinctiveness or importance in our studies.

\section{GENERAL DISCUSSION}

Students tend to recall more memories from the beginning and the end of school terms than from other periods of the year. Since differences specific to the schools in Experiment 1 affected the recall distributions, this calendar effect is not likely to have been an artifact of other seasonal changes such as holidays (see Table 1). The results, however, also suggest some qualifications. In particular, we found little evidence for enhanced recall when one term immediately follows the next. Boundaries between most of the terms at Cornell College did not lead students to recall more events. The effective endpoints were those in which the beginning or the end of a term adjoined a vacation, especially the beginning and the end of the entire 


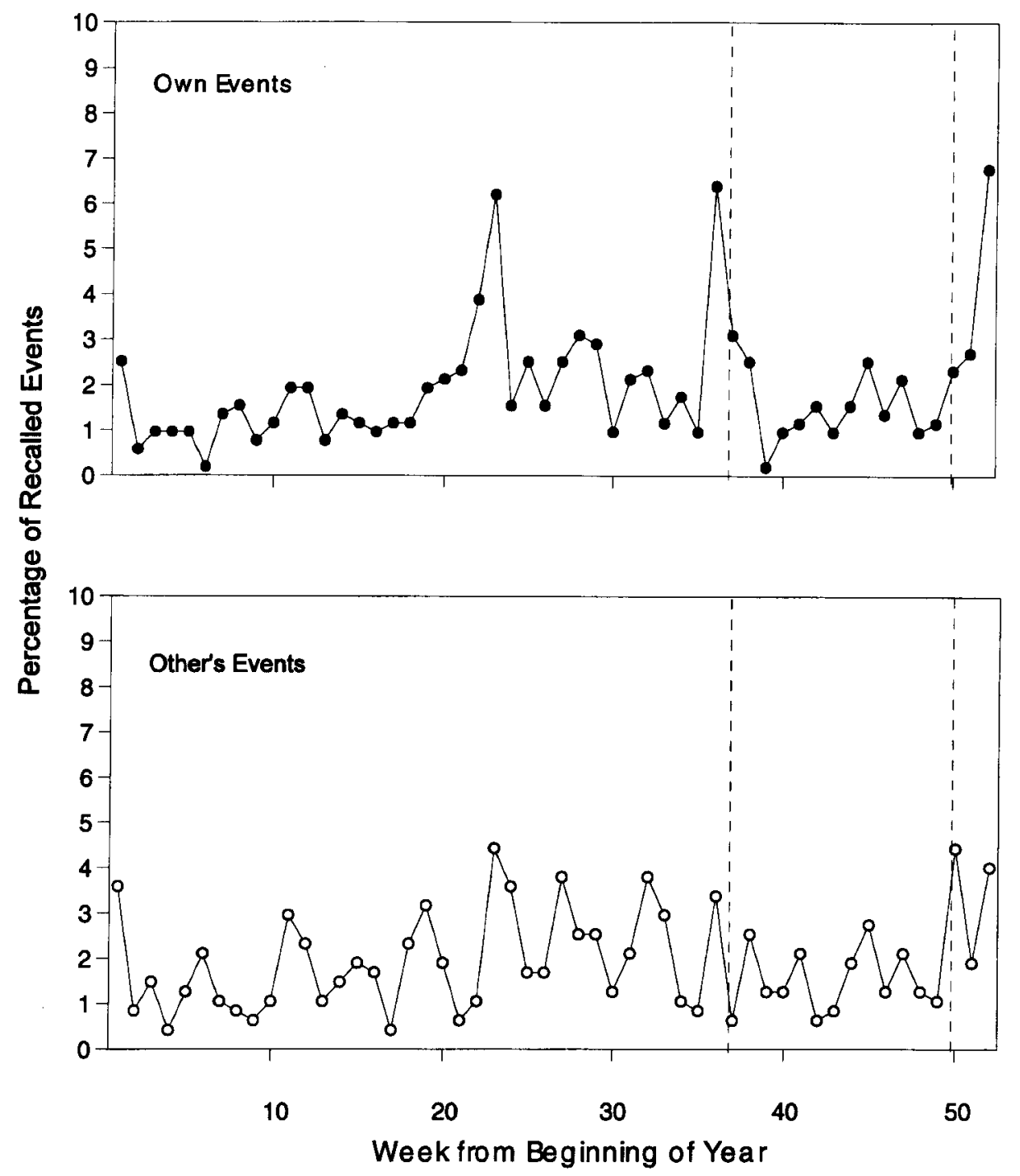

Figure 5. Percentage of recalled events by weeks for students reporting events that happened to them (top panel) and for students reporting events that might have happened to a classmate (bottom panel). The $x$-axis shows weeks in 1994, beginning with January 1 . Vertical lines show the position of the term boundaries at Northwestern.

school year. This accords with Robinson's (1986, p. 160) thesis that, psychologically, "temporal periods are defined in terms of requisite activities" and that "the relationship between temporal periods derives from one or more contrastive features... [including] at least one contrast of activity (e.g., work vs. vacation)."

The results of Experiments 2-4 help pinpoint the source of the calendar effect. Although one possibility is that events near school endpoints are more important than other events, we found in all three studies that students did not rate events near the endpoints as more important than events that occurred at other times. In Experiment 2, the difference between endpoint and non-endpoint events was in the direction predicted by the importance hypothesis but was not significant; in Experiment 3, the differ- ence was significantly in the opposite direction. Students in Experiment 4 rated the distinctiveness of the events, rather than their personal import, but the difference between endpoint and non-endpoint events remained negligible. We also considered the possibility that students were incorrectly dating events too close to the endpoint. In Experiment 2 , we had students date events whose true time of occurrence was known. But although there was evidence for inaccuracy in the students' dates, they did not appear to drift toward endpoint positions. The results of Experiment 3, however, support the idea that endpoints can aid retrieval. Providing students an explicit set of term cues maintained or enhanced the calendar effect, whereas providing them alternative cues (holidays like Valentine's Day) decreased it. 
Table 3

Mean Number of Recalled Events per Week and Rated Distinctiveness for Items Occurring Near a Term

Boundary and Elsewhere in the Year (Experiment 4)

\begin{tabular}{|c|c|c|c|}
\hline \multirow[b]{2}{*}{ Group } & \multirow[b]{2}{*}{$n$} & \multicolumn{2}{|c|}{ Position of Event } \\
\hline & & Term Boundary & Other Weeks \\
\hline \multicolumn{4}{|c|}{ Mean Number of Events Recalled Per Week } \\
\hline Event & 108 & 0.145 & 0.088 \\
\hline Pseudo-event & 97 & 0.099 & 0.091 \\
\hline \multicolumn{4}{|c|}{ Mean Distinctiveness Rating ( $0-10$ scale $)$} \\
\hline $\begin{array}{l}\text { Event } \\
\text { Pseudo-event }\end{array}$ & $\begin{array}{l}52 \\
32\end{array}$ & $\begin{array}{l}6.35 \\
4.81\end{array}$ & $\begin{array}{l}6.21 \\
5.06\end{array}$ \\
\hline
\end{tabular}

\section{An Explanatory Framework}

Our work implicates retrieval from long-term memory as the cause of the calendar effect, with endpoints serving as retrieval cues. But it would be incorrect to view these results as showing merely that people can use endpoint cues to aid recall. With the exception of Experiment 3, these cues were ones that the students themselves furnished, not ones that we imposed upon them. Even in Experiment 3, the cues consisted merely in labels on a calendar rather than the more explicit prompts of traditional cued recall. Our claim, then, is not merely that people can recall events in response to endpoint cues, but that they generate and use the cues as accustomed ways of locating events that happened to them.

The theoretical question, then, is why people would rely on such endpoint cues. To get a grip on this question, let us suppose that when people attempt to retrieve events from autobiographical memory, they construct a query or probe for the type of incident they are trying to recall. In common with other theories of autobiographical memory, we can also assume that their success in retrieving an incident depends on the degree of similarity between properties of the probe and properties of the incident as encoded (see, e.g., Conway, 1996; Kolodner, 1983; Williams \& Hollan, 1981). The closer the descriptors in the probe come to the properties of the event, the greater the probability of bringing all the stored information about it to mind. In this context, optimal probes will have two important qualities: specificity (the probe will contain as many descriptors as possible) and accuracy (the descriptors should each be true of the event). Specificity and accuracy trade off, since one can achieve accuracy on the cheap by being vague (e.g., an event that happened in 1993), and one can achieve specificity at the expense of falsehood (e.g., an event in which we went fishing with Ernest Hemingway).

Within this framework, school endpoints have an advantage because they provide a means to construct very specific and accurate probes based only on general information about the school. You realize that there must have been such endpoints simply on the grounds that you were in school during the year in question. This implies that you must have gotten to school at the beginning of the year by some means or other, you must have found a place to live, you must have gone through the normal start-of-semester academic rituals, and so on. Thus, the endpoints are part of a web of generic information about school that you can use to interrogate very long-term memory for more personal facts: They have many implications about the kinds of episodes that autobiographical memory must contain. It is possible that students originally encoded incidents at the endpoints as parts of an academic calendar schema, but it is also possible that the calendar increases retrieval at the endpoints simply by focusing students' attention on related memories.

This framework is also consistent with other findings from our experiments. First, since school-related events are more likely to match the endpoint probes than are nonschool events, we would expect the calendar effect to be largely the result of local increases in school items, as we observed. Second, events that match endpoint probes need not be more important or distinctive than events from other times of the year. Important or distinctive events may have many encoded properties or properties that differ from those of other events, but these characteristics do not ensure that the events will match endpoint probes. Third, probes based on holidays, birthdays, and similar regularly occurring events can be quite accurate (e.g., an event when I had a festive dinner with my family), but they may lack specificity (our participants had 18 or more years of holiday gatherings). For this reason, students may not use holiday probes without special prompting. Finally, retrieval of events through endpoint cues does not imply that people should misdate events as occurring too close to the endpoint. People may estimate the dates, as a further cognitive step, on the basis of the content of the relevant event, as in current "reconstructive" theories of dating (see, e.g., Friedman, 1993).

The question remains, however, why students prefer school boundaries or vacation breaks over other cues that share specificity and accuracy. Why don't students go about recalling the year's events using themes like their social relations to peers or parents, jobs, participation in religious or political groups, or other nonacademic pursuits? We know from Experiment 3 that students are capable of recalling such events when they are reminded of them, but why don't they spontaneously use these cues instead of academic landmarks? Part of the answer may be that students do sometimes recall events that fit into these themes, but because these events are timed differently for different students, they tend not to be visible in plots such as those shown in Figure 1. There is clear evidence for thematically related items in the events that our students described, and these groupings may be the results of alternative retrieval strategies. For example, one student in the school condition of Experiment 3 listed the following items among the events she recalled: ${ }^{8}$

1. Drove to my home with prospective boyfriend and another friend to borrow my father's beer-making equipment (February 9, 1991).

2. Received a dozen roses in a vase in an arrangement, from prospective boyfriend (February 14, 1991).

3. Kissed goodnight by prospective boyfriend and consider him no longer prospective (February 17, 1991). 
4. Friend in physics makes me tell her all about my boyfriend (February 18, 1991).

5. Took my boyfriend to dinner for his birthday (April 19, 1991).

6. Flew to boyfriend's home (July 25, 1991).

7. Drove back to house, had a barbecue and met some of my boyfriend's friends (July 29, 1991).

8. My boyfriend came back to Chicago (September 25, 1991).

9. Brought boyfriend home for Thanksgiving (November 27, 1991).

10. Boyfriend left, spent the day downtown with friends; drove home to Michigan in a snowstorm (December 15, 1991).

These items obviously constituted an important stream of activity for this student, and similar groupings are fairly common in other students' descriptions. (See Barsalou, 1988; Brown, Shevell, \& Rips, 1986; and Conway, 1996, for further evidence of these "autobiographical sequences" or "extended event timelines.") The timing of such sequences is largely idiosyncratic, however, except when they intersect more common landmarks, such as Valentine's Day (item 2 in the above list), Thanksgiving (item 9), or the beginning and end of fall quarter (items 8 and 10). Hence, effects of social relations and other themes that are not synchronized with the calendar will be smeared in time plots such as that in Figure 1.

The calendar effect, however, is not merely the result of averaging over students with similar academic schedules and different social schedules. For one thing, if there were no tendency for individual subjects to cluster events near school endpoints, our analyses in Experiments 1, 3, and 4 would not have produced significant calendar effects (all tests involved subject $\times$ effect error terms).

\section{Alternative Theories}

Although our results point to retrieval as one source of the calendar effect, it is reasonable to consider the possibility that the effect might be due to encoding of events at the endpoints or to changes that occur in the trace of the events during storage. Encoding theories are, of course, possible explanations of serial position curves in free recall (e.g., Feigenbaum \& Simon, 1962). Because the calendar effect resembles a kind of within-term serial position function, encoding theories may also be helpful in dealing with our results.

A potential encoding explanation is that students are more likely to attend to events near term boundaries and to represent them in more detail than events from other parts of the year. This type of account, however, seems to conflict with the results on importance from Experiments 2-4. If endpoint events are more attention getting and elaborately encoded, students ought to rate them as more important or distinctive than other events, contrary to our findings.

Perhaps the way we phrased the importance question was too vague to direct students to the relevant type of im- portance or distinctiveness, but other possible measures appear to do no better than rated importance. For example, if endpoint events receive more elaborate encoding, we might expect students' descriptions to be longer for these items. But, in fact, the length of the descriptions for endpoint events in Experiment 3 was about the same as for the remaining events: For the school group, endpoint items were 41.5 characters long on average, and for other items, 43.4 characters; for the holiday group, endpoint items were 36.3 characters, and for other items, 38.9 characters. Much the same was true of the events from Experiment 4. Furthermore, if the smaller number of recalled events from non-endpoint positions was truly due only to lack of encoding, then later cuing of these events ought not to access them. Experiment 3, however, revealed increased recall for such events with holiday cues. It is also possible to resuscitate importance (and encoding) by noting that students in Experiments 3 and 4 rated the importance of only the events they had recalled. Perhaps if we had access to all events that students experience (unrecalled, as well as recalled), importance would prove a better predictor. This possibility awaits further study, but it is worth noting that the recognition procedure in Experiment 2 was not restricted in the same way to free-recalled events, and it, too, produced little support for the importance of importance. Moreover, the pilot study that we described in Experiment 2 collected importance ratings near the time the events occurred and again yielded no significant effect. (See also Shum \& Rips, in press.)

These results seem to tell against the idea that students are more likely to encode events at school endpoints, but this does not mean that such events never receive special treatment. Incidents that occur when a freshman arrives on campus for the first time may be dramatic enough to produce very rich memories, as Pillemer et al. (1988; Pillemer et al., 1986) have claimed. This may account for differences between the freshmen and upperclassmen in recall of events from the beginning of the school year in Experiment 1 . The calendar effect, however, depends on more than just this starting point. It is also possible that students encode events near school endpoints in special ways because these events bear relevance to the life tasks that students face (Cantor \& Kihlstrom, 1985). When students think about their role, these events may come readily to mind (M. A. Conway, personal communication, January 30, 1997). But this hypothesis, as an explanation of the calendar effect, is incomplete, since it raises the question of why such encoding increases recall in ways that are not tapped by the importance ratings, and it shades into a retrieval explanation. ${ }^{9}$

Storage explanations face some of the same difficulties as encoding theories. If the cause of the calendar effect were only that traces of non-endpoint events fade faster than those of endpoint events, then it is hard to understand why merely displaying the names of holidays on a calendar would allow students to recall more non-endpoint items. Events could also change their temporal locus during storage in a way that would increase the number of reported 
events at the endpoints. We tested one version of this idea in the date-bias hypothesis and found no support for it, but other possibilities along these lines may do better. For example, Huttenlocher et al. (1988) and Rubin and Baddeley (1989) have proposed very similar models of memory for the temporal location of events that include assumptions about boundaries. According to models of this type, the location of an event can be represented by a symmetrical distribution on the time continuum. Students estimate the date of an event by sampling from this distribution. However, if the sampled date falls outside a known boundary for items of the type in question, students either fail to report the event or report it as occurring near the boundary. For example, if the sampled date of a school event, such as attending a class session of English 312, is before the beginning of the school year, then students will either fail to report the event or report it as happening at the beginning of the school term. These models are better able to handle the results on dates from Experiment 2 since they need not predict bias toward the term's beginning or end.

Unfortunately, sampling theories of dating do less well in predicting the shape of the recall distributions and thus do not explain the calendar effect. To see this, consider events that actually happened on opposite sides of a school endpoint - say, catching a plane back to school in the fall and attending the first class of English 312 . By assumption, the sampled date for these events will be in the wrong temporal segment on some proportion of trials, as in the example of the preceding paragraph. If students suppress these events, then they will tend to report fewer items near the endpoints than in the middle of the terms, contrary to the calendar effect. So suppose instead that students report these events, assigning them a date near the correct side of the boundary (e.g., a date just prior to the beginning of school for catching a plane and a date just after the beginning of school for attending English class). This strategy leads to local maxima of events at the boundary positions, but the shape of the recall distribution is not the typical bow-shaped curve that appears within terms in Figure 1. Instead, simulations of these theories show that the predicted distribution is W-shaped - that is, concave downward in the term's central position. This is because events that happen before the term in question (e.g., catching a plane) or after it (having Christmas dinner at home) will not be assigned dates within the term, reducing the total number of items that would otherwise appear within the term's initial and final segments. By contrast, no such depletion takes place for events around the middle of the term, since nearly all are reported at their sampled positions. Although it may be possible to add assumptions to these models to bring them into line with the data, we suspect that approaches based entirely on errors in dating will not be completely successful. ${ }^{10}$

\section{Conclusion}

Our results point to the possibility that the calendar effect is the result of people using endpoints to access their memories of the year's events. Recalling the start of the school year, for example, may prompt memories for related events (catching the plane to school, attending the first session of English 312) that happened at about the same time. A year's worth of events is obviously a vast assemblage of episodes, many having little more in common than the arbitrary fact of having occurred between January 1 and December 31 of a specific calendar year. Calendar endpoints may provide an entry point into this collection of events and help organize the process of recollecting them.

Our hunch is that what makes the endpoints prominent in retrieval is their perceived control over a person's activities, particularly changes in these activities. The endpoints determine where people are (hometown or vacation town), what people they encounter (home friends or vacation friends), what daily schedule they keep (work schedule or vacation schedule), and these factors in turn delimit the types and qualities of activities that are possible for them. For example, the rhythm of a social relationship, such as the one our student chronicled above, is apt to be quite different when a boyfriend comes back for fall quarter in September than after he leaves at the end of the quarter in December. Of course, the endpoints themselves have no causal powers and do not change people's activities directly. But people represent the endpoints as part of a system of expectations that dictates what they can do. What the present results show is that this system is also capable of reminding them of what they did.

\section{REFERENCES}

AURIAT, N. (1993). My wife knows best: A comparison of event dating accuracy between the wife, the husband, the couple, and the Belgium population register. Public Opinion Quarterly, 57, 165-190.

Baddeley, A. D., Lewis, V., \& Nimmo-Smith, I. (1978). When did you last . . . ? In M. M. Gruneberg, P. E. Morris, \& R. N. Sykes (Eds.), Practical aspects of memory (pp. 77-83). New York: Academic Press.

BARSALOU, L. (1988). The content and organization of autobiographical memories. In U. Neisser \& E. Winograd (Eds.), Remembering reconsidered (pp. 193-243). Cambridge: Cambridge University Press.

Bourdieu, P. (1977). Outline of a theory of practice. Cambridge: Cambridge University Press.

Bradburn, N. M., RupS, L. J., \& ShevelL, S. K. (1987). Answering autobiographical questions: The impact of memory and inference on surveys. Science, 236, 157-161.

BrEwER, W. F. (1988). Memory for randomly sampled autobiographical events. In U. Neisser \& E. Winograd (Eds.), Remembering reconsidered (pp. 21-90). Cambridge: Cambridge University Press.

Brown, N. R., Sheveli, S. K., \& RiPs, L. J. (1986). Public events and their personal context. In D. C. Rubin (Ed.), Autobiographical memory (pp. 137-158). Cambridge: Cambridge University Press.

Bruce, D., \& van Pelt, M. (1989). Memories of a bicycle tour. Applied Cognitive Psychology, 3, 137-156.

Cantor, N., \& Kinlstrom, J. F. (1985). Social intelligence: The cognitive basis of personality. In P. Shaver (Ed:), Self, situations, and social behavior (pp. 13-33). Beverly Hills, CA: Sage.

Chase, W. G., \& Simon, H. A. (1973). The mind's eye in chess. In W. G. Chase (Ed.), Visual information processing (pp. 215-281). New York: Academic Press.

Conway, M. A. (1990). Autobiographical memory. Buckingham, U.K.: Open University Press.

CONWAY, M. A. (1996). Autobiographical knowledge and autobiographical memory. In D. C. Rubin (Ed.), Remembering our past (pp. 67-93). Cambridge: Cambridge University Press.

Davidson, D. (1969). The individuation of events. In N. Rescher (Ed.), Essays in honor of Carl G. Hempel (pp. 216-234). Dordrecht: Reidel. 
ESTES, W. K. (1985). Memory for temporal information. In J. A. Michon \& J. L. Jackson (Eds.), Time, mind, and behavior (pp. 151-168). Berlin: Springer-Verlag.

Evans-Pritchard, E. E. (1940). The Nuer: A description of the modes of livelihood and political institutions of a Nilotic people. Oxford: $\mathrm{Ox}$ ford University Press, Clarendon Press.

Feigendaum, E. A., \& Simon, H. A. (1962). A theory of the serial position effect. British Journal of Psychology, 53, 307-320.

Fodor, J. A., Bever, T. G., \& Garrett, M. F. (1974). The psychology of language. New York: McGraw-Hill.

FRIEDMAN, W. J. (1993). Memory for the time of past events. Psychological Bulletin, 113, 44-66.

FuHRMAN, R. W., \& WYER, R. S. (1988). Event memory: Temporal-order judgments of personal life experiences. Journal of Personality \& Social Psychology, 54, 365-384.

GlenBERG, A. M. (1987). Temporal context and recency. In D. S. Gorfein \& R. R. Hoffman (Eds.), Memory and learning: The Ebbinghaus Centennial Conference (pp. 173-190). Hillsdale, NJ: Erlbaum.

Goldman, A. (1970). A theory of human action. Englewood Cliffs, NJ: Prentice-Hall.

Hanson, C., \& HiRST, W. (1989). On the representation of events. Journal of Experimental Psychology: General, 118, 136-147.

Huttenlocher, J., Hedges, L., \& Prohaska, V. (1988). Hierarchical organization in ordered domains: Estimating the dates of events. Psychological Review, 95, 471-484.

KOLODNER, J. L. (1983). Maintaining memory organization in dynamic long term memory. Cognitive Science, 7, 243-280.

LEACH, E. R. (1961). Rethinking anthropology. London: Athlone Press.

LinTON, M. (1975). Memory for real-world events. In D. A. Norman \& D. E. Rumelhart (Eds.), Explorations in cognition (pp. 376-404). San Francisco: Freeman.

LoFTUS, E. F., \& MARBURGER, W. (1983). Since the eruption of Mt. St. Helens, has anyone beaten you up? Improving the accuracy of retrospective reports with landmark events. Memory \& Cognition, 11, 114-120.

MALINOWSKI, B. (1927). Lunar and seasonal calendar in the Trobriands. Journal of the Royal Anthropological Institute, 57, 203-215.

Means, B., Nigram, A., Zarrow, M., LofTus, E. F., \& Donaldson, M. S (1989). Autobiographical memory for health-related events (Report no. 2, Series 6). Hyattsville, MD: National Center for Health Statistics.

NeWTSON, D. (1973). Attribution and the unit of perception in ongoing behavior. Journal of Personality \& Social Psychology, 28, 28-38.

Pillemer, D. B., Goldsmith, L. R., PANTer, A. T., \& White, S. H. (1988) Very long-term memories of the first year in college. Journal of Experimental Psychology: Learning, Memory, \& Cognition, 14, 709-715.

Pillemer, D. B., RhineharT, E. D., \& White, S. H. (1986). Memory of life transitions: The first year in college. Human Learning, 5, 109-123.

Poulton, E. C. (1989). Bias in quantifying judgments. Hillsdale, NJ: Erlbaum.

ReISER, B. J., Black, J. B., \& Abelson, R. P. (1985). Knowledge structures in the organization and retrieval of autobiographical memories Cognitive Psychology, 17, 89-137.

RoBinson, J. A. (1986). Temporal reference systems and autobiographical memory. In D. C. Rubin (Ed.), Autobiographical memory (pp. 159188). Cambridge: Cambridge University Press.

Rosch, E. (1975). Cognitive reference points. Cognitive Psychology, 7 , 532-547.

Rubin, D. C., \& Baddeley, A. D. (1989). Telescoping is not time compression: A model of the dating of autobiographical memories. Memory \& Cognition, 17, 653-661.

Rubin, D. C., \& KozIN, M. (1984). Vivid memories. Cognition, 16, 81-95.

SCHANK, R., \& ABELSON, R. (1977). Scripts, plans, goals, and understanding. Hillsdale, $\mathrm{NJ}$ : Erlbaum.

Shum, M. S., \& RIPS, L. J. (in press). The respondent's confession. In M. Sirken, D. J. Herrmann, S. Schechter, N. Schwarz, J. Tanur, \& R. Tourangeau (Eds.), Cognition and survey research. New York: Wiley. Strube, G., \& Neubauer, S. (1988). Remember that exam? In M. M. Gruneberg, P. E. Morris, \& R. N. Sykes (Eds.), Practical aspects of memory: Current research and issues (Vol. 1, pp. 247-252). Chichester, U.K.: Wiley
Thompson, C. P., SKowronski, J. J., LARSEn, S. F., \& BetZ, A. L. (1996). Autobiographical memory. Mahwah, NJ: Erlbaum.

TVERSKY, A., \& KaHNEMAN, D. (1974). Judgment under uncertainty: Heuristics and biases. Science, 185, 1124-1131.

WAGENAAR, W. A. (1986). My memory: A study of autobiographical memory over 6 years. Cognitive Psychology, 18, 225-252.

Williams, D. M., \& Hollan, J. D. (1981). The process of retrieval from very long term memory. Cognitive Science, 5, 87-119.

\section{NOTES}

1. In addition, the calendar effect has some practical applications in the design of survey questions (see, e.g., Bradburn, Rips, \& Shevell, 1987). The effect suggests that when it is important to maximize the number of events that respondents recall, it may be reasonable to guide recall with work- or school-centered calendars that locate the events of interest with respect to endpoints.

2. There were 366 days in 1988 (a leap year), and thus 52 full weeks plus 2 additional days. We have omitted the events from the last fractional week (i.e., the days of December 30 and 31) from Figure 1, but they are included in the statistical analyses reported later. Chicago freshmen recalled 14 events from these 2 days, Chicago upperclassmen recalled 16, Cornell freshmen 20, and Cornell upperclassmen 24

3. We thank Paul Estin for pointing out this possibility

4. It is also possible to plot the overall proportion of events that students recall in each of the divisions of the year. For both Chicago and Cornell upperclassmen, this plot reveals a steadily increasing trend for the academic terms from the beginning of January through the end of December. There is also elevated recall for the summer months at both schools, even when a correction is made for the length of the summer.

5. In a further study at two Chicago-area high schools, we examined the effects of calendars in which term boundaries and vacation breaks sometimes coincide and sometimes do not (in one school, Christmas vacation occurred within the first semester). The results of this study suggested that calendar effects are largest when the boundaries and breaks coincide than when either occurs separately.

6. We also analyzed the serial order in which students recalled events in view of the fact that recall order followed chronological order in some autobiographical studies (e.g., Bruce \& van Pelt, 1989). For this purpose, we calculated for each student the Spearman correlation between the order in which he/she listed the events and the dates of these events. The results showed small positive correlations: Mean $r_{\mathrm{s}}$ for Chicago freshmen and upperclassmen were .19 and .17 , respectively, and the means for Cornell freshmen and upperclassmen were .26 and .31 . These means were all significantly greater than 0 by two-tailed $t$ tests (after transforming the $r_{\mathrm{s}}$ s to Fisher's $z$, all $p \mathrm{~s}<.05$ ). However, the low magnitude of the correlations suggests that not all students used order of events in the year as a basis for recall. Although some students produced high values of $r_{\mathrm{s}}$ many others produced correlations near 0 . (There was little evidence of recall in reverse chronological order, the smallest individual correlation being $-: 68$.) Evidence for chronological recall in earlier studies has generally appeared when the events themselves were of a restricted type (e.g., events on a bike tour in Bruce \& van Pelt, 1989; movies in a campus series in Huttenlocher, Hedges, \& Prohaska, 1988 ), and it is possible that these additional constraints encourage serial order.

7. Thompson et al. (1996, chap. 7) reported signed-error data from a series of studies in which students wrote down one personal incident each day over several months and were then tested at the end of the period by having them provide dates for the event descriptions. These data also showed a tendency for events to be moved toward the middle of the experimental range. In most of these studies, the experimental period (event reporting and test) occurred within a semester or quarter. Thus, displacement toward the middle was displacement away from academic boundaries, in accord with our own results. At the same time, it is not possible to distinguish the effects of the academic boundaries from the effects of the experimental period in these experiments. (Thompson et al. also reported one longer term study that lasted more than one semester, but they did not analyze possible effects of academic terms.) 
8. The subject did not recall the events in the order listed here. We have rearranged the events chronologically to clarify the relations among them.

9. Of course, the intervals near the school endpoints or the endpoints themselves may be important, even though the specific events that students recall are not (D. B. Pillemer, personal communication, November 15,1993 ). It is not clear on a pure encoding theory, however, how the importance of endpoint intervals produces greater recall for events that are not important. By contrast, retrieval theories clarify the relation between endpoints and neighboring events since the endpoints can serve as retrieval cues for the events.

10. It is possible to obtain better predictions by dropping the assumption that endpoints determine whether an event is reported and assuming instead that the variance of the event's distribution increases with distance from the nearest endpoints (Estes, 1985). According to this model, temporal information about an event becomes less precise during stor- age the farther the event is from the endpoint of a term. This produces within-term bow-shaped functions when the difference in variance is large. A model along these lines (as well as certain versions of the distinctiveness hypothesis) predicts that the absolute error of dates (i.e. |subjective date - true date|) would be smaller for events near the endpoints, whereas the data of Experiment 2 (not plotted here) exhibit a trend in the opposite direction. It is also difficult for such a model to account for the results of Experiment 3. If loss of temporal information takes place in storage, it is not clear why retrieval cues should alter the frequency profiles, as in Figure 4.

(Manuscript received November 26, 1996; revision accepted for publication March 10, 1997.) 